\title{
Risk Analysis of Philippine Power Engineering Project in EPC Mode :Take S Company's D Project in the Philippines as an Example
}

\author{
Zeng Fenyu $^{1,}$, Shi Guoping ${ }^{* 1}$, Zhang $\mathrm{Di}^{1}$, Yvonne Pauline Matira ${ }^{2}$ \\ ${ }^{1}$ Shanghai University of Electric Power, Shanghai, China \\ ${ }^{2}$ Batangas State University, Batangas, Philippines
}

\begin{abstract}
Since the "One Belt And One Road" initiative, EPC general contracting mode has become the main contracting mode for China's power construction enterprises to undertake overseas projects. It not only requires the general contractor to have strong design and construction capacity, but also strong risk control ability. Taking the D project of S company in the Philippines as an example, this paper combines the characteristics of EPC mode with the actual project, analyses the main risks existing in the project construction process from the perspective of power enterprises, and puts forward countermeasures and relevant suggestions to deal with the risks.
\end{abstract}

\section{EPC general contracting concept and characteristics of overseas power projects}

EPC (Engineering, Procurement, Construction) refers to the electric power enterprises entrusted by the owner, in accordance with the contract of engineering construction project design, procurement, construction, commissioning to realize the whole process of contract, and the comprehensive quality, safety, cost and time limit for a project. It is the main mode adopted by international power engineering project at present [1]. Main features are presented as:

(1) the general contractor is responsible for the entire project implementation process, which requires unified coordination of design, construction and procurement.

(2) the total contract amount is fixed, and cost management is its core task.

(3) project evaluation is difficult because it is a complex systematic engineering with numerous construction links and large time span, which makes project evaluation difficult.

(4) the natural environment, laws and regulations, cultural differences, policy guidance and other local factors of the project determine whether the EPC general contract project is successful or not.

(5) FIDIC(International Federation of Consulting Engineers.) is adopted in overseas EPC general contracting project contracts, and adopted in technical standards and specifications internationally [2] .

(6) the overseas EPC general contracting project has a large scale, long construction period, large management span and numerous uncertain factors, and the general contractor has to bear most of the risks.
The above features of the overseas EPC general contracting mode greatly increase the risk of the general contracting project. This paper sorts out the risk of the Philippine power engineering project based on the real feeling of the project risk during the internship in the Philippine engineering project, interviews with relevant departments and staff, and theoretical knowledge of EPC project management.

\section{Risk analysis of EPC general contracting project in the Philippines}

\subsection{Natural risks}

The Philippines has a monsoon-type tropical rain forest climate, with high temperature, sufficient rain, high humidity, typhoons, frequent earthquakes, tsunamis and other natural disasters. Every year from June to October is the rainy season in the Philippines, which is characterized by heavy rainfall, which will seriously affect the construction schedule and lead to project delay. Meanwhile, climate-induced outbreaks of dengue fever are common. According to official statistics, dengue cases in the Philippines have surged this year, with at least 450 deaths. Domestic workers are more at risk than local workers. It not only affects the physical and mental health of employees, but also makes the general contractor subject to fines from the Philippine government, which will increase the cost of the general contractor. Thus, natural risk not only causes damage to employees and mechanical equipment with the cost increasing, but also is a major factor affecting the project schedule.

\footnotetext{
* Corresponding author: 1084045796@qq.com
} 


\subsection{Contract risks}

In EPC mode, the main contract is called the soul of project construction. All work is carried out around meeting the requirements of the main contract. The main contract is also the main basis for the owner to supervise, approve and accept the whole project, which runs through the whole process of construction. In the early stage of contract risk negotiation, the contractor may not specify the terms and conditions of EPC project contract or identify the terms and responsibilities in a vague way. This will easily lead to loopholes in the terms. Once there is a dispute between the two parties afterwards, the contractor may be at a disadvantage in the negotiation process if they cannot provide a clear contract term. For example, if these problems are not identified and prevented in time at the early stage of the contract, the construction period will be delayed, the design cost will even increase, and the interests of the general contractor will be damaged.

\subsection{Production safety risks}

Power engineering projects in the Philippines, like those in China, are subject to supervision and management by safety regulators, but the differences in laws and regulations bring many risks to domestic enterprises, mainly including the following two categories. First is the risk of major production safety accidents. When a major safety accident happens, not only do the casualties of employees bring losses to the enterprise, but more importantly, the Philippine labor department investigates the impact on the enterprise. Major safety accidents shall be reported to the ministry of labor for filing within 24 hours. After filing, the ministry of labor will organize an investigation team to intervene and track down unexpected findings during the investigation of accidents. Meanwhile, the right to stop work will be exercised for accidents caused by serious lack of safety management and repetitive violations of regulations. Secondly, environmental protection accident risk is mentioned. China's attention to environmental protection has reached a certain level, but the Philippines' labor department and the DENR(Department of Environment and Natural Resources) have a stronger environmental supervision on foreign companies than in China. For example, all diesel and gasoline generators are required to have a DENR exhaust emission permit, which is valid for only one year. The penalties involved in such violation are very strict, including but not limited to the maximum fine of 100,000 pesos per day until the standard is met.

\subsection{Visa risks}

In order to protect the interests of the Philippine labor force and increase the employment rate of its own personnel, the Philippine government usually sets strict limits on the number and proportion of foreign workers. For example, the proportion of local employees should not be less than $50 \%$ of the total number of employees. And migrants must have a labor visa, while a business visa does not allow them to work outside meetings. At present, it seems that the Philippine government's policy on the control of the application for work visa to the Philippines is changing constantly, and the application review is becoming more and more strict, which often leads to the delay of the application for work visa. Delayed handling not only increases costs in various aspects, but also indirectly affects the psychological mood of employees, which becomes a potential hidden danger factor of the project. Because there is a short period of illegal labor in the application process, we will also face the risk of inspection and penalty of the owner as well as the local immigration bureau. In addition, the construction delay caused by irresistible factors such as natural environment will also bring in visa risks.

\subsection{Technical risks}

Technical risks are mainly manifested in the design and construction links. In the design process, the owner often uses American or European standards, and most of domestic design engineers aren't familiar with international standard. Due to the understandings deviation of the design department and the owner towards design and specifications in the process, the time of design and approval would be affected in a result[3]. In the construction process, due to cultural differences, the owner often holds opposing views on the construction process and technology of the construction personnel. Owners tend to work step by step, and domestic construction personnel in the working process of the longterm have accumulated a lot of flexible work methods, most of them are completely reliable in practice. But owners are always in an international engineering mind, they would make the project rectification which may seriously affect the timeline.

\subsection{Labor risks}

The employees employed by S company in the D project in the Philippines mainly include local employees of the Philippines and domestic employees, so the employment risks focus on both domestic employees and local employees. The employment risks of Chinese employees are mainly reflected in the brain drain caused by the failure to adapt to the overseas engineering environment, and the improper employee selection. Overseas power engineering projects usually have a relatively closed environment, a small range of activities, a monotonous life, a long period of separation from their families and food problems, etc., so domestic employees who cannot adapt to the overseas working environment would choose to resign. However, for international projects, this situation will bring greater employment risks to overseas projects. Once the employees choose to leave, the general contractor has to choose suitable substitutes in a short time. The human resources department of overseas projects will face more difficulties and procedures. In terms of the employment of overseas projects, if only considering their professional skills but ignoring factors such as language communication and understanding of overseas projects, it 
will give rise to a lot of inconvenience in the future. Local workers in the Philippines have various abilities, low productivity, high protection from the labor department as well as strike culture. Labor rights and interests of the local labors are protected from local department seriously, and differentiation of employment can lead to litigation. If the Philippines staff to report the Chinese engaged in low skilled jobs such as sweeping the floor, which consists of the reasons for career opportunities violation, it will be in strict screening of the employment situation of the project. So once the survey is true, most likely will be the result of the large area of shutdown.

\section{Risk response measures}

\subsection{Measures to deal with natural environmental risks}

At the beginning of the project, we should conduct a survey on the natural environment of the project site, and arrange specific response plans according to the survey results. For the prevention of dengue fever, we can reduce the breeding of mosquitoes by means of regular spraying of insecticides and standardizing the sanitary conditions of living and office areas. At the same time, the establishment of groups, timely reporting of the epidemic situation. In response to frequent earthquakes in the Philippines, managers conduct safety drills to ensure employees understand how to save themselves and others. Rainy season construction will bring a lot of inconvenience and danger, the group leader should emphasize the awareness of safety production to ensure personnel safety.

\subsection{Measures to deal with contract risks}

At the early stage of contract negotiation, it's significant to hire professional and technical personnel to participate in the contract negotiation, clarify technical standards such as examination and approval, eliminate possible ambiguity as much as possible, and clearly stipulate the agreement reached by both parties in the form of contract [4]. So as to avoid disputes in the execution of the contract.

\subsection{Measures to deal with production safety risks}

Strictly abide by local laws and regulations and respect local religion, culture and customs. Raise awareness of environmental risks and drive environmental assessment as a priority to ensure project legality and compliance. It's necessary to strengthen the safety training of construction personnel, learn from the international safety management experience to improve the safety management system of overseas projects, and cultivate the awareness and culture of safety production.

\subsection{Measures to deal with visa risks}

Be familiar with Philippine visa processing procedures, understand the problems frequently encountered in
Philippine visa processing, and form an efficient processing process. Prepare the visa application for the staff in advance, and actively cooperate with the Philippine government for the transfer of other types of visa to work visa, and conduct effective communication to get the work visa quickly.

\subsection{Measures to deal with technical risks}

The main contract should be carefully studied, and the unfeasible contract terms should be fully paid attention to in the initial negotiation to reduce the risk of subsequent construction. The site construction environment is complex, the person in charge of the subcontractor should supervise the construction process and check and accept the project according to the contract standards. In the selection of subcontractors should also fully investigate the subcontractor's qualifications and ability, in order to reduce the risk of construction.

\subsection{Measures to deal with labor risks}

While selecting personnel, we should not only consider the professional qualification and experiences of the staff, but also consider whether the physical and mental quality of the staff can withstand the difficult as well as monotonous working and living environment overseas. Improve the career development path and incentive mechanism of international talents to prevent brain drain[5]. For the recruitment of local employees, it is advisable to cooperate with local human resources companies, which can not only transfer local employment risks, but also achieve a good control effect on local employees.

\section{Summary}

The overseas EPC general contracting project not only brings broader development space for power enterprises, but also makes them face unprecedented challenges. This paper takes S company' D project in the Philippines as the research object, according to the characteristics of the EPC mode and the actual project, analyses the overseas EPC project construction process of natural risk, contract risk, production safety risk, visa risk, technology risk and the employment risk, and proposes the corresponding strategies which may provide advices for overseas project construction.

\section{Acknowledgement}

Fund project: Project of ministry of education: "research on training system of engineering and technical talents with international vision", project no.18JDGC004;

Key project of Shanghai philosophy society: "innovation research on international talents training system of applied engineering under the background of One Belt And One Road" Project no.A1906 


\section{References}

1. Li Mingfang, HongShui River, Vol.29 No.3 , (2010)

2. Nacl Q Bunni, The FIDIC Forms of Contract Oxford ,Blackwell Publishing Ltd , (2015)

3.Yang rong,Zhang weifang, Engineering Journal of Wuhan University, Vol.51 No.9, (2018)

4. Wang Zhiguo, Value engineering, Vol.66 No.21, (2017)

5. Zeng fenyu ,Li gege, Practice in Foreign Economic Relations and Trade, Vol.360 No.1, (2019) 